\title{
COVID-19 and idiopathic nephrotic syndrome in children: systematic review of the literature and recommendations from a highly affected area
}

\author{
William Morello ${ }^{1}\left[\right.$ (]) Federica Alessandra Vianello ${ }^{1} \cdot$ Emanuele Proverbio $^{1} \cdot$ Licia Peruzzi $^{2} \cdot$ Andrea Pasini $^{3}$. \\ Giovanni Montini ${ }^{1,4}$ (D)
}

Received: 29 August 2021 / Revised: 2 October 2021 / Accepted: 4 October 2021 / Published online: 23 October 2021

(c) The Author(s), under exclusive licence to International Pediatric Nephrology Association 2021

\begin{abstract}
Background Coronavirus Disease 2019 has spread from China as a global pandemic, Italy being one of the earliest affected countries. The infection displays a more complicated and often fatal course in adults with a history of kidney disease, while it does not seem to affect children in the same way. Pediatric patients with idiopathic nephrotic syndrome (INS), with or without chronic immunosuppressive therapy, are at greater risk of infections which may also trigger relapses.

Objectives We performed a systematic review of the literature to identify all articles on SARS-CoV-2 infections in children with INS in order to describe the severity of all SARS-CoV-2 infections reported in children with INS, to evaluate the risk of new onset and relapses associated with SARS-CoV-2 infection, and to draw recommendations on their management and vaccination. The search was conducted on the following databases: MEDLINE (via Pubmed), Google Scholar, and Web of Science. The search methodology used with the selected free text terms or MesH was ("nephrotic syndrome" OR "idiopathic nephrotic syndrome") and ("covid 19" OR "severe acute respiratory syndrome coronavirus 2" OR "2019-nCoV" OR "SARS-CoV-2").

Results The literature search provided 36 records. After screening for their relevance to the topic, 11 studies were selected. Two additional publications were identified through the reference list of all included articles and 13 articles were included in the review. A total of 43 cases of children with INS and SARS-CoV-2 infection have been reported; the course of the disease was mild for most patients with low need of respiratory support and no death in high income countries. In 5 patients, the infection was complicated by relapse, which anyway showed a good response to steroids. Two children had a new onset of INS during a SARS-CoV-2 infection.

Conclusions Children with INS, with or without immunosuppression, are not at higher risk of severe SARS-CoV-2 infection. Relapse is a possible complication, but steroid treatment is safe and effective. After summarizing the evidence, we have suggested recommendations for the management of children with INS during the pandemic and the vaccination campaign.
\end{abstract}

Keywords Idiopathic nephrotic syndrome · COVID-19 - SARS-CoV-2 infection · Vaccination · Children

Giovanni Montini

giovanni.montini@unimi.it

1 Pediatric Nephrology, Dialysis and Transplant Unit, Fondazione IRCCS Ca' Granda, Ospedale Maggiore Policlinico, 20122 Milano, Italy

2 Pediatric Nephrology Unit, Regina Margherita Children's Hospital, AOU Città Della Salute E Della Scienza Di Torino, Turin, Italy

3 Nephrology and Dialysis Unit, Department of Pediatrics, Azienda Ospedaliero Universitaria, Policlinico Sant'Orsola-Malpighi, Bologna, Italy

4 Department of Clinical Sciences and Community Health, University of Milan, Milan, Italy

\section{Introduction}

Coronavirus Disease 2019 (COVID-19), caused by the newly emerged SARS-CoV-2 virus, has abruptly spread from China as a global pandemic, Italy being one of the earliest affected countries [1].

As of August 11, 2021, 4,409,090 cases have been confirmed in Italy, of which $689,248(15.6 \%)$ were in the 0-19 years old group [2]. Compared to adults, children are more often either asymptomatic or display milder manifestations with a much lower mortality rate [3]. Despite earlier studies suggesting pediatric infection as mainly being 
characterized by self-limiting upper respiratory symptoms [3], exceptions have emerged, such as the multi-system inflammatory syndrome in children (MIS-C) [4]. While a history of kidney disease is a risk factor for poorer outcomes in adults, it does not seem to affect children in the same way $[5,6]$.

Idiopathic nephrotic syndrome (INS) is the most common pediatric glomerular disease, affecting 1.15-16.9 per 100000 children [7]. In the majority of patients, the clinical course is characterized by frequent relapses, often related to infectious events. Most INS children require chronic immunosuppressive therapy to control disease activity [7]. Immunosuppressed children are at greater risk of infectious diseases, including viral infections [8].

We have reviewed the existing literature on the diffusion and severity of SARS-CoV-2 infections in children with INS, with the intention to suggest indications for the management of such patients during the pandemic. Even though the pandemic is regressing in most European countries and in the USA, we believe these recommendations could be helpful for pediatric nephrologists and pediatricians, due to the continuous spread in countries with scarce economic resources, the uncertainties about the vaccination campaign, as well as the possible emergence of new variants partially covered by vaccines.

\section{Methods}

For the main objectives of this project, a working group of pediatric nephrologists from three main centers of the most affected area during the pandemic in Italy was established, including five members.

The panel conducted a systematic search of the published literature to identify all the articles relevant for this review through a search and selection process in the following databases: MEDLINE (via Pubmed), Google Scholar, Web of Science. The search methodology used with the selected free text terms or MesH was: ("nephrotic syndrome" OR "idiopathic nephrotic syndrome") and ("covid 19" OR "severe acute respiratory syndrome coronavirus 2" OR "2019nCoV" OR "SARS-CoV-2").

The articles included had no time frame. Only articles concerning pediatric patients were considered for the analysis. Grey literature was excluded. Searches were carried out on the 15th of July 2021 and rerun on the 5th of August 2021. The search was particularly focused on the following aspects: severity of SARS-CoV-2 infection in children with INS, new onset and relapse of INS related to SARS-CoV-2 infection, SARS-CoV-2 vaccination in children with INS. To reduce selection bias, two independent reviewers (F.A.V., E.P.) screened titles and abstracts to identify potential articles for inclusion. An additional manual search was also carried out over the references of the main chosen articles to collect information about the studies deemed relevant. A third reviewer (W.M.) later revised and verified the extracted information. Any discrepancy about inclusion was resolved through discussion. The PRISMA flowchart for article inclusion is displayed in Fig. 1.

Once the final list of articles was selected, all data were reviewed and analyzed by the full panel of experts.

After data extraction, the working group summarized the existing evidence and formulated recommendations covering the main aspects of the management of children with INS during SARS-CoV-2 pandemic and COVID-19 vaccination campaign. Due to the paucity of data on the topic, we did not consider it needful to formally evaluate the methodological quality of the studies included. To draw up specific recommendations, the authors combined the preexisting knowledge about the disease with the available evidence from literature.

\section{Results}

The literature search provided 36 records. After removing duplicates and screening titles and abstracts for their relevance to the topic, a total of 11 articles were selected. The reference list of all included articles was screened to identify papers potentially related to the topic. Two additional publications were added, for a total of 13 articles included in the review. Figure 1 describes the article selection process and Table 1 summarizes the main findings of all included articles.

\section{Summary of the evidence}

\section{SARS-CoV2 spreading among children with idiopathic nephrotic syndrome}

To date, only 3 studies, all performed in Italy, have addressed the diffusion of SARS-CoV-2 among children with INS [5, $9,10]$.

At the end of April 2020, in the context of the Italian Society of Pediatric Nephrology (ISPN), a national study involving 1572 pediatric patients, with either chronic kidney disease or on immunosuppression, was performed in order to assess the impact of COVID-19 in this population [5]. The incidence of SARS-CoV-2 infection was retrospectively assessed by means of a phone interview, with no case of severe COVID-19 reported Among the 652 children with INS included in the study, none reported a previous SARSCoV-2 infection, documented by a nasal swab test.

After the first wave, a seroprevalence study was performed on the same population by the ISPN [9]. 178 randomly selected patients together with their family 


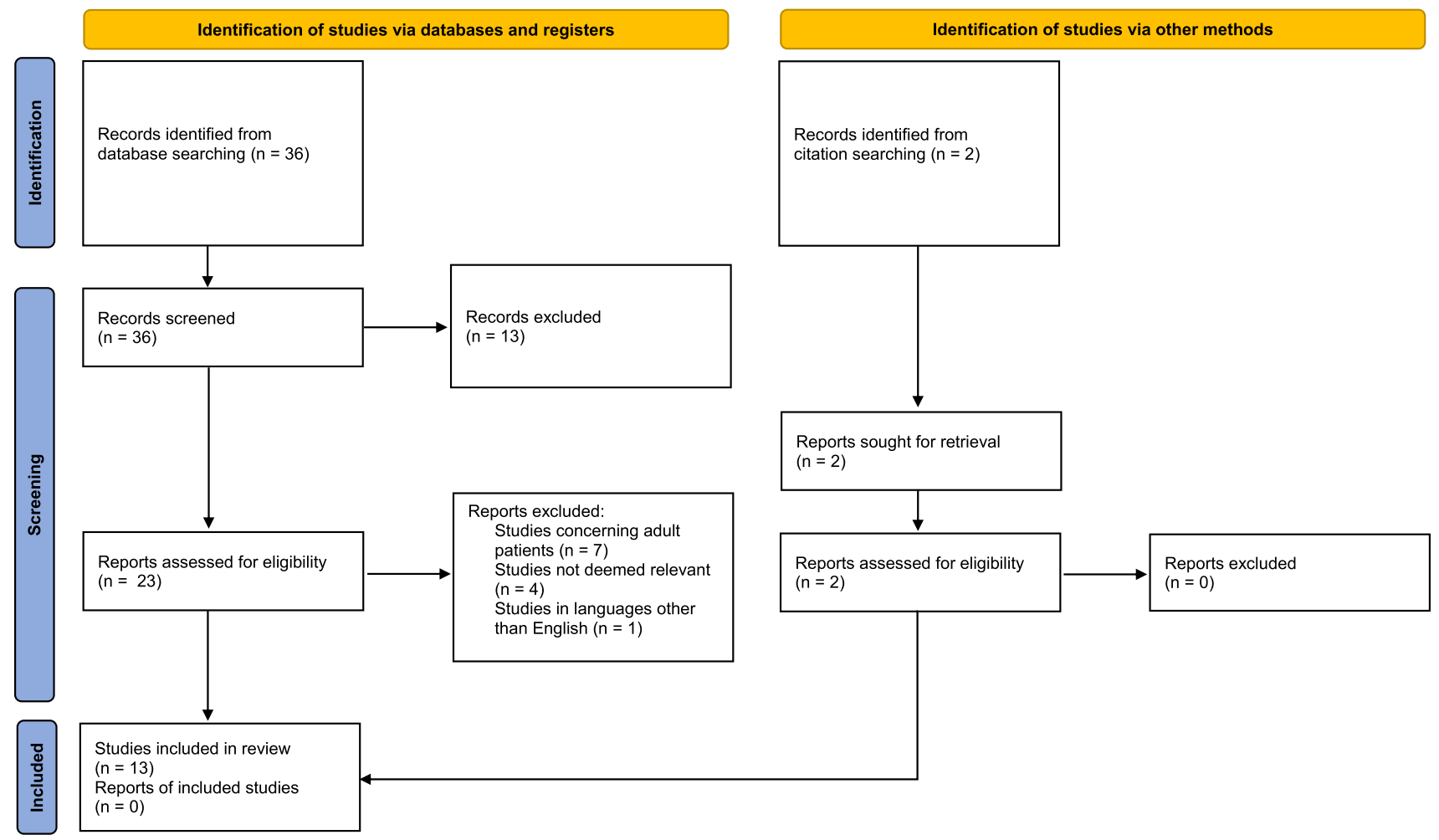

Fig. 1 PRISMA 2020 flow diagram

members, and 161 children with a history of symptoms suggestive for a viral infection, included in the previous study [5], were tested. The seroprevalence among children with kidney diseases was low and did not differ from that of the pediatric healthy Italian population. 110 patients with INS were included, of whom 58 had previously reported nonspecific infectious symptoms. Among these, only $2 / 110(1.8 \%)$ patients tested positive for SARS-CoV-2 IgG. The first had an asymptomatic SARSCoV-2 infection and the other one presented upper airway symptoms (published and unpublished data). Moreover, four children with INS tested negative, even if they had at least one positive family member.

The third study performed during the first wave by Angeletti et al. investigated, through a phone-based inquiry, the diffusion of SARS-CoV-2 among a pediatric population of 159 children affected by INS on immunosuppressive therapy with anti-CD20 monoclonal antibodies [10]. No patients reported symptoms compatible with COVID-19, even in the six families in which there was an infected member, like the ISPN study.

According to these studies, pediatric patients with INS on immunosuppressive treatment are not at increased risk of SARS-CoV-2 infection.

\section{Severity of SARS-CoV2 infection in children with INS}

Eight studies reported a total of 43 cases of children affected by INS with SARS-CoV-2 infection (Table 2). The course of the disease was mild for most affected children. Marlais et al. described the severity of the infection in 18 pediatric patients with a kidney disease, including three with INS [6]. None was admitted to the intensive care unit or died. Noninvasive ventilation was required only for $3 / 18$ patients, but the underlying disease was not specified. A similar clinical course of SARS-CoV-2 infection was also reported in an additional 10 children with INS described in other case series [9,11-15]: symptoms were mostly absent or mild and only one needed oxygen therapy. The ongoing immunosuppressive therapy was not reduced, while an increased dose of steroids was required after relapse in five patients [11-14]. In September 2020, Marlais et al. described the widest cohort of children treated with immunosuppressive medications for kidney diseases affected by COVID-19 [16]. 30/113 (27\%) of the reported patients were affected by INS. The outcome of SARS-CoV-2 infection was compared between the immunosuppressed population and a cohort of 582 children from 21 European countries. There was no significant difference for the main items, such as admission to the hospital $(60 \%$ 
Table 1 Summary of studies included

\begin{tabular}{|c|c|c|}
\hline Author & Patients with INS & Main findings \\
\hline Mastrangelo et al. [5] & 652 children with INS & $\begin{array}{l}\text { - None reported a previous SARS-CoV-2 infection docu- } \\
\text { mented by a nasal swab test }\end{array}$ \\
\hline Angeletti et al. [10] & 127 patients on therapy with anti-CD20 antibodies & $\begin{array}{l}\text { - No patients reported symptoms compatible with COVID- } \\
19\end{array}$ \\
\hline Marlais et al. [6] & $\begin{array}{l}3 \text { patients with INS and SARS-CoV-2 infection on IS } \\
\text { therapy }\end{array}$ & $\begin{array}{l}\text { - No admission to intensive care unit } \\
\text { - No death }\end{array}$ \\
\hline Melgosa et al. [12] & 4 patients with INS SARS-CoV-2 infection on IS therapy & $\begin{array}{l}\text { - 2/4 asymptomatic } \\
\text { - 2/4 INS relapse treated with steroids }\end{array}$ \\
\hline Morello et al. [9] & $\begin{array}{l}\text { - } 110 \text { INS patients on IS therapy tested for SARS-CoV-2 } \\
\text { IgG } \\
\text { - only } 2 \text { INS patients (1.8\%) with a previous SARS-CoV-2 } \\
\text { infection }\end{array}$ & $\begin{array}{l}\text { - Benign clinical course in both patients ( } 1 \text { asymptomatic; } 1 \\
\text { with mild upper airways symptoms) } \\
\text { - No IS therapy modifications needed }\end{array}$ \\
\hline Marlais et al. [16] & $\begin{array}{l}\text { 30/113 patients with INS on IS therapy and SARS-CoV-2 } \\
\text { infection }\end{array}$ & $\begin{array}{l}\text { - Mild clinical course for most patients } \\
\text { - } 4 / 113 \text { cases of deaths (all from low-income countries; } \\
\text { underlying disease not specified) }\end{array}$ \\
\hline Meshram et al. [15] & $\begin{array}{l}1 \text { patient with INS on IS therapy and SARS-CoV-2 infec- } \\
\text { tion }\end{array}$ & $\begin{array}{l}\text { - Mild course of disease } \\
\text { - IS therapy was stopped }\end{array}$ \\
\hline Basalely et al. [11] & 1 patient with INS off-therapy and SARS-CoV-2 infection & $\begin{array}{l}\text { - INS relapse during SARS-CoV-2 infection-oxygen } \\
\text { therapy required } \\
\text { - Remission in } 7 \text { days with oral steroids }\end{array}$ \\
\hline Enya et al. [13] & $\begin{array}{l}\text { Relapse in a } 3 \text { years old INS patient on low-dose steroid } \\
\text { treatment with SARS-CoV-2 infection }\end{array}$ & $\begin{array}{l}\text { - Relapse during steroid tapering after a recent onset of } \\
\text { steroid sensible INS } \\
\text { - Mild SARS-CoV-2 infection } \\
\text { - Remission after full-dose steroid treatment }\end{array}$ \\
\hline Al Yazidi et al. [14] & $\begin{array}{l}\text { Relapse in a } 10 \text { years old INS patient with SARS-CoV-2 } \\
\text { infection }\end{array}$ & $\begin{array}{l}\text { - Hospitalization and albumin infusions for worsening } \\
\text { edema } \\
\text { - Discharged after } 48 \mathrm{~h} \text { with steroid treatment } \\
\text { - Mild clinical course }\end{array}$ \\
\hline Harambat et al. [17] & $\begin{array}{l}\text { Comparison between INS relapses rate from March } 16 \text { to } \\
\text { August 30, } 2020 \text { and the same period in } 2019 \text { in France }\end{array}$ & $\begin{array}{l}\text { - Similar relapse rate during the first wave in } 2020 \text { and the } \\
\text { corresponding period of } 2019\end{array}$ \\
\hline Alvardo et al. [20] & $\begin{array}{l}\text { Onset of INS in a } 15 \text { years old patient with SARS-CoV2 } \\
\text { infection }\end{array}$ & $\begin{array}{l}\text { - Respiratory involvement } \\
\text { - Typical INS onset (anasarca, hypoalbuminemia, proteinu- } \\
\text { ria, hyperlipidemia) } \\
\text { - Treatment with chloroquine, azithromycin and methylpred- } \\
\text { nisolone pulses for } 5 \text { days with clinical improvement } \\
\text { - No available information about remission }\end{array}$ \\
\hline Shah et al. [21] & $\begin{array}{l}\text { Onset of INS in an } 8 \text { years old patient with SARS-CoV-2 } \\
\text { infection }\end{array}$ & $\begin{array}{l}\text { - No viral symptoms } \\
\text { - Typical onset (oedema, proteinuria, hypoalbuminemia, } \\
\text { hyperlipidemia) } \\
\text { - Treatment with oral steroids } \\
\text { - Remission in } 7 \text { days }\end{array}$ \\
\hline
\end{tabular}

Table 2 Summary of reported patients with INS and SARS-CoV-2 infection

\begin{tabular}{|c|c|c|}
\hline Patients with INS and SARS-CoV-2 infection & $n=43$ & $\begin{array}{l}\text { - Mild clinical course for most patients } \\
\text { - Low need of respiratory support } \\
\text { - No deaths reported in high income countries }\end{array}$ \\
\hline Patients with SARS-CoV-2 infection complicated by INS relapse & $n=5$ & - Good response to steroids \\
\hline Patients with new onset of INS during SARS-CoV-2 infection & $n=2$ & $\begin{array}{l}\text { - Typical clinical presentation } \\
\text { - Sensitivity to steroids in one patient } \\
\text { - No available information about remission for } \\
\text { the other patient }\end{array}$ \\
\hline
\end{tabular}


vs. $62 \%$ ), fever (65\% vs. $65 \%$ ) and mechanical ventilation (4\% vs. $4 \%$ ). In contrast with all previous studies, 4 deaths due to COVID-19 in immunosuppressed children were reported; the underlying kidney diseases of these patients were not specified. It must be noted that all deaths were reported from low-income countries. Therefore, to date, no cases of death due to SARS-CoV-2 infection are reported among pediatric patients with INS in Western countries, symptoms are mostly mild, and the need of intensive care is low.

\section{Relapses of INS related to SARS-CoV-2 infection}

To date, 5 cases of relapse during a documented SARSCoV-2 infection are reported in pediatric patients with INS (Table 2). Melgosa et al. described the course of SARSCoV-2 infection in 16 pediatric patients with kidney diseases [12], of whom four had a steroid-dependent INS on chronic immunosuppression. In all patients the viral infection was mild; no child needed intensive care admission or died. Two of the 4 INS patients experienced a relapse during the SARS-CoV-2 infection; both were easily managed with oral steroids. Enya et al. reported the case of a 3-year-old Japanese boy who developed SARS-CoV-2 infection with a progressive increase of proteinuria five weeks after the onset of a steroid-sensitive NS, during steroid tapering [13]. Fever and periorbital oedema were present at the time of relapse. A full dose steroid treatment allowed for prompt remission, within one week. A similar benign course with a good response to steroid therapy was reported in a 10-year-old boy from Oman [14]. Basaley et al. described a relapse in a febrile child affected by both SARS-CoV-2 and Streptococcus Agalactie [11]. He needed oxygen therapy, antibiotic and diuretic treatment and albumin infusion. Prophylactic enoxaparin was administrated for the increased risk of thrombosis related to INS relapse and SARS-CoV-2 infection. Remission was achieved 7 days after oral steroids initiation.

In a French national study by Harambat et al. retrospectively comparing the number of relapses in children with INS from March 16 to August 30, 2020 (0.78 relapse/ patient-year), with the same period in 2019 (0.91 relapse/ patient-year), the risk of relapse was not increased during the COVID-19 pandemic [17]. Nonetheless, no SARSCoV-2 infections were identified. It has been reported that the restrictions in place during the lockdown period have reduced the diffusion of many infectious diseases among children [18] and this may have had a positive effect on the total number of INS relapses, counteracting the risk related to SARS-CoV-2 infection itself, moreover the ongoing immunosuppression could have played a role in mitigating the incidence of relapse in these children.

Infectious diseases, especially viral upper respiratory infections, trigger INS relapses [19]. Thus, from the beginning of the pandemic, main concerns were related to the possible effect of SARS-CoV-2 infection on the activity of the disease in children with INS. According to the literature, relapse is a possible complication of SARS-CoV2 infection in children with INS, steroid treatment is safe and effective, but the incidence of relapses seems unchanged during the pandemic, when compared to previous years.

\section{New onset of INS during SARS-CoV-2 infection}

The onset of a de novo INS in association with a SARSCoV2 infection has been reported in 2 pediatric patients [20, 21] aged 8 and 15 years, respectively (Table 2). While, the 8 -year-old patient did not have the typical symptoms of a viral infection, the 15-year-old patient presented with fever, myalgias, worsening dyspnea and bilateral pleural effusion, with reticular interstitial opacity at the chest X-ray. In both patients, the clinical picture was complicated by progressive generalized oedema and weight gain. Urine and blood tests showed proteinuria, hypoalbuminemia and hypercholesterolemia, as expected at INS onset. The first patient was treated with oral steroids and remission was achieved in 7 days. The older one was treated with chloroquine, azithromycin and boluses of methylprednisolone for 5 days with clinical improvement, but no information about remission is available.

Onset of INS during SARS-CoV-2 infection is not a common event and it seems to have a regular clinical course with no complications related to the administration of steroid therapy during the infection.

\section{Vaccination against SARS-CoV-2 in children with INS}

Specific data on vaccination against SARS-CoV-2 in paediatric patients with INS are lacking, nonetheless we were able to review general information on available vaccines and the evidence from adults and immunocompromised patients.

The four EMA-approved COVID19 vaccines have shown clinical efficacy against SARS-CoV-2 [22-25]. Both the mRNA-1273 (Spikevax) and BNT162b2 (Comirnaty) vaccines are composed of lipid-nanoparticles encasing pieces of non-replicating single-stranded nucleoside-modified mRNA encoding for the spike protein of the SARS-CoV-2 [22, 23]. The ChAdOx1 (Vaxzevria) and Ad26.COV2.S (Jannsen) vaccines are based on recombinant, replication-deficient adenovirus vectors, modified to express the spike protein of SARS-CoV-2 on the surface of the cells, allowing for the immune response [24, 25].

Both mRNA vaccines have shown a proven efficacy, with a good safety profile, and have been approved in children aged 12-17 years old [26, 27]. The EMA-authorized replication-deficient adenovirus vaccines (Vaxzevria and Janssen) are yet to be approved in the paediatric age groups. 
The possibility of INS relapse due to the vaccine seems unlikely, nonetheless a few cases have been reported in the adult population. Bomback et al. [28] collected 5 described cases of minimal change disease (MCD) relapses, following the first dose of SARS-CoV-2 vaccination (3 Comirnaty, 2 Vaxzevria), in adults, aged 22-60 years old. All achieved a complete remission after immunosuppressive treatment. It must be noted that 1 out of the 4 patients who completed the vaccination schedule had a second relapse following the second dose.

Five patients with de novo MCD related to SARS-CoV-2 vaccination with mRNA vaccines (4 Comirnaty, 1 Spikevax) were also reported by the same author [28]. Another case of MCD onset was described after Janssen vaccination [29]. All patients were above 50 years old and manifested symptoms around the first week from the first dose of vaccination. Steroid treatment led to partial or complete recovery in all patients. One patient was given the second dose followed by a relapse of proteinuria.

Even if the vaccination campaign in children is only at the beginning, to date, no relapses have been reported in pediatric patients with INS, following anti-SARS-CoV-2 vaccination. Moreover, recent data from a prospective cohort study of 80 children and young adults with INS did not show a difference in relapse rate during the 24-month follow-up between 19 patients who had received a vaccination and 61 who had not, even though this study did not include antiSARS-CoV-2 vaccinations [30].

Recent studies have shown that immunocompromised patients have a higher risk of developing persistent SARSCoV-2 infections [31, 32]. This may create either more pathogenic or more transmissible SARS-CoV-2 variants, which would have many public health and medical implications. Such patients should be prioritized for vaccination not only to protect them from SARS-CoV-2 but also to reduce persistent infections, a dangerous source of new variants [33]. Pediatric patients with INS on immunosuppressive treatment are not an exception. Nonetheless, a lower antibody response in a heavily immunosuppressed cohort of patients has been reported and a three dose schedule has been proposed to increase vaccine immunogenicity in this population [34].

Infections are one of the most common complications in children with INS and patients are recommended to follow the schedule of the healthy population for inactive vaccines [35]. However, live vaccines are generally contraindicated under immunosuppressive treatment [36].

Due to the paucity of data, there is no strong evidence on SARS-CoV-2 vaccination in children with INS, therefore the following conclusions are based on the panel's expert opinion. While SARS-Cov-2 infection shows a mild disease course in pediatric patients with INS on immunosuppressive drugs [16], with an incidence and severity of the disease comparable to that of the general pediatric population $[5,6$,
9], the vaccination of patients affected with INS, whether on immunosuppressive therapy or not, would appear to be an effective choice in both lowering the spread of the virus and preventing possible severe disease. In the pediatric population the hypothetical risk of relapse following the vaccination, even if present, could be offset by the more concrete chance of relapse related to SARS-CoV-2 infection itself $[11-14,37]$.

We believe that anti-SARS-CoV-2 vaccination should be performed in children with INS with or without immunosuppressive therapy, monitoring signs of potential relapse. Since both Adenovirus vaccines are not yet approved in children and have a warning note on patients taking immunosuppressive therapies, our advice is to use mRNA vaccines. This recommendation is also based on the overall preference of inactivated vaccines over live or attenuated ones in immunocompromised patients.

We would furthermore like to emphasize the importance of including pediatric patients with INS in prospective clinical trials in order to verify both the immunogenicity and risks of vaccination in this population.

\section{Recommendations}

After reviewing the available literature, the panel drew up the following recommendations. Considering the lack of controlled data in this area, the recommendations are mostly based on expert opinions.

\section{Management of immunosuppression during the pandemic}

I) We suggest continuing the ongoing chronic IS therapy in patients with INS, regardless of the pandemic situation, while patients and parents should be taught to report to their doctors any SARS-CoV-2 infection or related symptoms.

II) Immunosuppressive therapy should be initiated or intensified with no COVID-related concerns, if required for the management of INS.

\section{Restrictions}

III) We recommend that children affected by INS do not require more stringent protection measures compared to healthy peers, during the pandemic.

\section{SARS-Cov-2 infection in children with INS}

IV) We suggest to adopt the management protocol of healthy children, in the event of a SARS-CoV-2 infection in INS children in remission and treatment free. There is no need for pre-emptive hospitalization. 
Signs of disease relapse should be monitored closely (i.e., urine dipstick). In the case of a severe SARSCoV-2 infection, hospitalization and reduction of the IS therapy should be considered.

V) We suggest to continue the ongoing treatment and to avoid immediate hospitalization, in the event of an asymptomatic or mild SARS-CoV-2 infection in INS children, undergoing IS therapy. Signs of disease relapse should be monitored closely (i.e., urine dipstick). In the case of a severe SARS-CoV-2 infection, hospitalization and reduction of the IS therapy could be considered.

\section{Relapse}

VI) We suggest INS relapses to be treated with steroid therapy, following the standard guidelines and the good clinical practice. There is no reason to delay the initiation of steroid therapy during the pandemic.

VII) We suggest to handle SARS-CoV-2-related INS relapses according to the current clinical guidelines for the management of INS.

\section{Vaccinations}

VIII) We recommend vaccination against COVID-19 in all INS patients, following the age limits established by the drug control agencies (EMA/FDA).

IX) The vaccination should be preferentially performed with an mRNA vaccine, according to the age restrictions of adenovirus vector vaccines and especially in patients undergoing IS therapy.

$\mathrm{X}$ ) In case of an ongoing anti-CD20 therapy (i.e., rituxi$\mathrm{mab}$ ), vaccination should be postponed at least six months after the suspension of the treatment to allow for B-cell reconstitution and to maximize the response.

XI) After vaccination, relapse signs should be closely monitored (i.e., urine dipsticks).

XII) Vaccination should not be performed during relapses.

Data availability Not applicable.

Code availability Not applicable.

\section{Declarations}

Conflict of interest The authors declare no competing interests.

\section{References}

1. Fagiuoli S, Lorini FL, Remuzzi G (2020) Adaptations and lessons in the province of Bergamo. N Engl J Med 382:e71

2. Sorveglianza integrata COVID-19: i principali dati nazionali. https://www.epicentro.iss.it/coronavirus/sars-cov-2-sorveglian za-dati. Accessed 18 Aug 2021

3. Dong Y, Mo X, Hu Y, Qi X et al (2020) Epidemiological characteristics of 2143 pediatric patients with 2019 Coronavirus Disease in China. Pediatrics 145:e20200702. https://doi.org/10.1542/peds. 2020-0702

4. Nakra N, Blumberg D, Herrera-Guerra A, Lakshminrusimha S (2020) Multi-System Inflammatory Syndrome in Children (MISC) Following SARS-CoV-2 Infection: review of clinical presentation, hypothetical pathogenesis, and proposed management. Children (Basel) 7:69. https://doi.org/10.3390/CHILDREN7070069

5. Mastrangelo A, Morello W, Vidal E, Guzzo I et al (2020) Impact of COVID-19 pandemic in children with CKD or immunosuppression. Clin J Am Soc Nephrol 16:449-451. https://doi.org/10. 2215/CJN.13120820

6. Marlais M, Wlodkowski T, Vivarelli M, Pape L et al (2020) The severity of COVID-19 in children on immunosuppressive medication. Lancet Child Adolesc Health 4:e17-e18. https://doi.org/10. 1016/S2352-4642(20)30145-0

7. Noone DG, Iijima K, Parekh R (2018) Idiopathic nephrotic syndrome in children. Lancet 392:61-74. https://doi.org/10.1016/ S0140-6736(18)30536-1

8. Fishman JA (2009) Infection in solid-organ transplant recipients. N Engl J Med 357:2601-2614. https://doi.org/10.1056/NEJMR A064928

9. Morello W, Mastrangelo A, Guzzo I, Cusinato L et al (2021) Prevalence of SARS-CoV-2-IgG antibodies in children with CKD or immunosuppression. Clin J Am Soc Nephrol 16:1097-1099. https://doi.org/10.2215/CJN.00330121

10. Angeletti A, Drovandi S, Sanguineri F, Santaniello M et al (2020) COVID-19 in children with nephrotic syndrome on Anti-CD20 chronic immunosuppression. Clin J Am Soc Nephrol 15:14941495. https://doi.org/10.2215/cjn.06400420

11. Basalely A, Brathwaite K, Duong MD, Liu D et al (2021) COVID19 in children with kidney disease: a report of 2 cases. Kidney Med 3:120-123. https://doi.org/10.1016/j.xkme.2020.09.007

12. Melgosa M, Madrid A, Alvárez O, Lumbreras J et al (2020) SARS-CoV-2 infection in Spanish children with chronic kidney pathologies. Pediatr Nephrol 35:1521-1524. https://doi.org/10. 1007/s00467-020-04597-1

13. Enya T, Morimoto Y, Oshima R, Miyazaki K et al (2021) Nephrotic syndrome relapse in a boy with COVID-19. CEN Case Reports 10:431-434. https://doi.org/10.1007/ s13730-021-00587-w

14. Al Yazidi L, Al Nabhani D (2021) Coronavirus disease-2019 in children with nephrotic syndrome. Saudi J Kidney Dis Transpl 32:284-285. https://doi.org/10.4103/1319-2442.318544

15. Meshram VKB, Saha A, Patel HV et al (2021) Coronavirus disease-2019 in children with primary kidney disease: a case series. Saudi J Kidney Dis Transplant 32:218. https://doi.org/10.4103/ 1319-2442.318527

16. Marlais M, Wlodkowski T, Al-Akash S, Ananin P et al (2020) COVID-19 in children treated with immunosuppressive medication for kidney diseases. Arch Dis Child 106:798-801. https://doi. org/10.1136/archdischild-2020-320616

17. Harambat J, Allard L, Godron-Dubrasquet A (2021) Relapse rate of nephrotic syndrome in the time of COVID-19. Pediatr Nephrol 36:211-212. https://doi.org/10.1007/s00467-020-04814-x

18. Torretta S, Cantoni B, Bertolozzi G, Capaccio P et al (2021) Has Otitis Media disappeared during COVID-19 pandemic? A 
fortuitus effect of domestic confinement. J Clin Med 10:2851. https://doi.org/10.3390/jcm10132851

19. Uwaezuoke SN (2015) Steroid-sensitive nephrotic syndrome in children: Triggers of relapse and evolving hypotheses on pathogenesis. Ital J Pediatr 41:19. https://doi.org/10.1186/ s13052-015-0123-9

20. Alvarado A, Franceschi G, Resplandor E, Sumba J, Orta N (2020) COVID-19 associated with onset nephrotic syndrome in a pediatric patient: coincidence or related conditions? Pediatr Nephrol 36:205-207. https://doi.org/10.1007/s00467-020-04724-y

21. Shah SA, Carter HP (2020) New-Onset Nephrotic Syndrome in a Child Associated With COVID-19 Infection. Front Pediatr 8:471. https://doi.org/10.3389/FPED.2020.00471

22. Polack FP, Thomas SJ, Kitchin N, Absalon J et al (2020) Safety and efficacy of the BNT162b2 mRNA Covid-19 Vaccine. N Engl J Med 383:2603-2615. https://doi.org/10.1056/NEJMOA2034577

23. Baden LR, Sahly HM El, Essink B, Kotloff K et al (2020) Efficacy and safety of the mRNA-1273 SARS-CoV-2 vaccine. N Engl J Med 384:403-416. https://doi.org/10.1056/NEJMOA2035389

24. Voysey M, Clemens SAC, Madhi SA, Weckx LY et al (2021) Safety and efficacy of the ChAdOx1 nCoV-19 vaccine (AZD1222) against SARS-CoV-2: an interim analysis of four randomised controlled trials in Brazil, South Africa, and the UK. Lancet 397:99111. https://doi.org/10.1016/S0140-6736(20)32661-1

25. Sadoff J, Gray G, Vandebosch A, Cárdenas V et al (2021) Safety and Efficacy of single-dose Ad26.COV2.S vaccine against Covid19. N Engl J Med 384:2187-2201. https://doi.org/10.1056/ NEJMOA2101544

26. Frenck R, Klein N, Kitchin N, Gurtman A et al (2021) Safety, immunogenicity, and efficacy of the BNT162b2 Covid-19 vaccine in adolescents. N Engl J Med 385:239-250. https://doi.org/10. 1056/NEJMOA2107456

27. Ali K, Berman G, Zhou H, Deng W et al (2021) Evaluation of mRNA-1273 SARS-CoV-2 vaccine in adolescents. N Engl J Med. https://doi.org/10.1056/NEJMOA2109522

28. Bomback A, Kudose S, D'Agati V (2021) De Novo and relapsing glomerular diseases after COVID-19 Vaccination: what do we know so far? Am J Kidney Dis. https://doi.org/10.1053/J.AJKD. 2021.06.004

29. Lim J, Han M, Kim Y, Kim MS et al (2021) New-onset nephrotic syndrome after Janssen COVID-19 vaccination: a case report and literature review. J Korean Med Sci 36:e218. https://doi.org/10. 3346/JKMS.2021.36.E218

30. Angeletti A, Bruschi M, Bianchin S, Bonato I et al (2021) Vaccines and disease relapses in children with nephrotic syndrome. Clin J Am Soc Nephrol 16:937-938. https://doi.org/10.2215/CJN. 01890221

31. Choi B, Choudhary MC, Regan J, Sparks JA et al (2020) Persistence and evolution of SARS-CoV-2 in an immunocompromised host. N Engl J Med 383:2291-2293. https://doi.org/10.1056/ NEJMC2031364

32. Baang J, Smith C, Mirabelli C, Valesano AL et al (2021) Prolonged severe acute respiratory syndrome coronavirus 2 replication in an immunocompromised patient. J Infect Dis 223:23-27. https://doi.org/10.1093/INFDIS/JIAA666

33. Corey L, Beyrer C, Cohen MS, Michael NL et al (2021) SARSCoV-2 Variants in patients with immunosuppression. N Engl $\mathrm{J}$ Med 385:562-566. https://doi.org/10.1056/NEJMSB2104756

34. Kamar N, Abravanel F, Marion O, Couat C et al (2021) Three doses of an mRNA Covid-19 vaccine in solid-organ transplant recipients. N Engl J Med 385:661-662. https://doi.org/10.1056/ NEJMC2108861

35. Pasini A, Benetti E, Conti G, Ghio L et al (2017) The Italian Society for Pediatric Nephrology ( $\mathrm{SINePe}$ ) consensus document on the management of nephrotic syndrome in children: Part I-Diagnosis and treatment of the first episode and the first relapse. Ital J Pediatr 43:41. https://doi.org/10.1186/s13052-017-0356-x

36. Rubin LG, Levin MJ, Ljungman P, Davies EG et al (2013) 2013 IDSA clinical practice guideline for vaccination of the immunocompromised host. Clin Infect Dis 58:309-318. https://doi.org/ $10.1093 / \mathrm{cid} / \mathrm{cit} 816$

37. Doevelaar AAN, Hölzer B, Seibert FS, Bauer F et al (2020) Lessons for the clinical nephrologist: recurrence of nephrotic syndrome induced by SARS-CoV-2. J Nephrol 33:1369-1372. https:// doi.org/10.1007/s40620-020-00855-5

Publisher's note Springer Nature remains neutral with regard to jurisdictional claims in published maps and institutional affiliations. 